\title{
Correlation of Cardiovascular Risk Factors with Central Obesity and Multiple Body Mass Index in Korea
}

\author{
Bora Yoo', Hosuk Nam', In Cheol Hwang², Youngmin Park ${ }^{3, *}$ \\ 'Department of Family Medicine, Yonsei University College of Medicine, Seoul, Korea \\ ${ }^{2}$ Department of Family Medicine, Gachon University Gil Hospital, Incheon, Korea \\ ${ }^{3}$ Department of Family Medicine, National Health Insurance Service Ilsan Hospital, Goyang, Korea
}

Background: Body mass index (BMI) and waist circumference (WC) are associated with cardiovascular (CV) risk factors. The aim of this study was to investigate the correlation of CV risk factors by cross-tabulating central obesity with multiple BMI categories in Korea.

Methods: A total of 328,789 adults aged 30-84 years who completed health assessments for National Health Insurance in 2012-2013 in Korea were examined. The participants were divided into two WC and five BMI groups to investigate CV risk factors, including metabolic syndrome (MetS), hypertension, diabetes, and dyslipidemia.

Results: The proportions of central obesity and obesity were $24.2 \%$ and $39.5 \%$ in men and $19.4 \%$ and $28.1 \%$ in women, respectively, according to the Korean Society for the Study of Obesity and World Health Organization AsiaPacific Guideline criteria. The odds ratios (ORs) of CV risk factors in all sexes increased with increases in BMI and WC. Compared to the group with a normal WC and BMI, the adjusted ORs (95\% confidence intervals) for having MetS and diabetes in the centrally obese and highest BMI group (BMI $\geq 30.0 \mathrm{~kg} / \mathrm{m}^{2}$ ) were 35.95 (33.75-38.30) and 3.51 (3.26-3.77) in men and 29.22 (27.36-31.20) and 4.35 (4.02-4.70) in women, respectively. Participants who were centrally obese and obese (BMI $\geq 25.0 \mathrm{~kg} / \mathrm{m}^{2}$ ) had the strongest correlation with all CV risk factors compared with those who were not centrally obese or obese.

Conclusion: The presence of central obesity in multiple BMI categories may significantly identify individuals at increased risk of CV risk factors.

Keywords: Body Mass Index; Waist Circumference; Cardiovascular Diseases; Obesity; Diabetes Mellitus 


\section{INTRODUCTION}

The increase in the number of overweight and obese people is a growing public health concern worldwide. It is known that having a high body mass index (BMI) is an important risk factor for chronic diseases, including cardiovascular disease (CVD), type II diabetes, and hypertension. $^{1-4)}$ Some studies have suggested that BMI is just as important as waist circumference (WC) in predicting and screening for metabolic syndrome (MetS) and its components. ${ }^{5,6)}$

Although BMI has traditionally been used as an anthropometric index for CVD risk in many epidemiological studies, WC, which reflects central adiposity and body fat distribution, can be superior to BMI in predicting CVD risk factors. ${ }^{7-11)}$ On the other hand, some studies have reported a stronger positive association between cardiovascular risk factors, such as hypertension and lipid and glucose concentrations, and both BMI and WC together than BMI or WC alone. ${ }^{12-14)}$

In Korea, some studies have shown that either BMI or WC is strongly associated with cardio-metabolic risk or CVD, respectively. ${ }^{15)}$ The correlation of cardiovascular risk factors measured by both BMI and WC simultaneously has not yet been reported in Korea.

As a part of the National Health Insurance Service National Sample Cohort (NHIS-NSC) in South Korea, the goal of this analysis was to investigate the correlation of cardiovascular risk factors by cross-tabulating central obesity with multiple BMI categories in this population.

\section{METHODS}

\section{Study Design and Population}

All Korean nationals are eligible to enroll in the Korean National Health Insurance Service (KNHIS). Thus, almost all of data in this health system are centralized in large databases, including diagnostic codes, prescription drugs, procedures, medical costs, and dental services. A unique identification number, called the Resident Registration Number, is assigned to all Korean residents at birth. Because this num- ber is used by both the Korean government and the KNHIS, there are no duplicate or omitted health records.

This study was based on data from the NHIS-NSC 2002-2013 (NHIS-2014-2-008), which was provided by the KNHIS. The data comprises 1,025,340 nationally representative random participants, which amounted to approximately $2.2 \%$ of the entire population of the KNHIS in 2002. The data were produced by the KNHIS using a systematic sampling method to generate a representative sample from all $46,605,433$ Korean residents in 2002. This database includes all medical claims and the data of health assessments that the NHIS has served every year or two, filed from January 2002 to December 2013. ${ }^{16)}$

This study was cross-sectional in design and based on data from medical claims and health assessments from 2012-2013. We recruited 354,494 participants from 30-84 years of age who had NHIS health assessments during 2012-2013 out of the 1,025,340 NHIS-NSC respondents from 2002-2013. We excluded 23,838 participants who reported a history of cancer (all cancer types) and CVD at enrollment as well as 245 who died during the same year that they had the health assessments. In addition, 1,622 participants with a low BMI (less than $15 \mathrm{~kg}$ / $\mathrm{m}^{2}$ ), short stature (1.3 $\mathrm{m}$ or less), or incomplete data for BMI, blood pressure, serum cholesterol, fasting serum glucose, alcohol consumption, and smoking were excluded. This resulted in a final analytical sample of 328,789 people, including 169,011 men and 159,778 women (Figure 1).

Our study design was reviewed and approved by the Institutional Review Board of the National Health Insurance Service Ilsan Hospital in Gyeonggi-do, Korea (2015-5-012). The requirement for written informed consent was waived.

\section{Data Collection}

The health assessments followed a standard procedure and were conducted by medical staff at hospitals nationwide. Using a standardized questionnaire, the participants were asked to report their alcohol consumption, smoking habits (never, former, or current smoker), intensity

\section{\begin{tabular}{|c|}
\hline Participants who had \\
National Health Insurance Service \\
health assessment during 2012-2013 $(n=354,494)$ \\
\hline
\end{tabular}}

\begin{tabular}{|c|c|}
\hline & $\begin{array}{r}\text { Participants who reported a history of } \\
\text { cancer and cardiovascular disease }(\mathrm{n}=23,838)\end{array}$ \\
\cline { 2 - 3 } & \begin{tabular}{|c|c|} 
Participants who died during the health \\
assessment $(\mathrm{n}=245)$
\end{tabular} \\
\cline { 2 - 3 } & $\begin{array}{c}\text { Participants with low BMI, short stature or } \\
\text { incomplete data for BMI, blood pressure, } \\
\text { serum cholesterol, fasting glucose, alcohol } \\
\text { consumption and smoking (n=1,622) }\end{array}$ \\
\hline
\end{tabular}

Final analytical sample of participants are included. $(n=328,789$, males $=169,011$, female $=159,778)$
Figure 1. Selection scheme for study population. BMl, body mass index. 
of exercise, residential area, household income, current diseases, and family disease history. The completed questionnaires were reviewed by trained staff and subsequently entered into a database.

Measurements of fasting serum glucose and total cholesterol were obtained during a medical evaluation after the patient had fasted overnight. Each hospital had internal and external quality control procedures in place that were overseen by the Korean Association of Laboratory Quality Control. Data for weight and height were obtained with the participants in light clothing. Blood pressure was measured in the seated position with a mercury sphygmomanometer or an automatic manometer. BMI was calculated as weight over height squared (kg/ $\mathrm{m}^{2}$ ). WC was measured at the horizontal plane between the inferior costal margin and the iliac crest at the mid-axillary line (recorded in $\mathrm{cm})$.

\section{Definition of Main Exposure and Outcome Variables}

Central obesity was defined as a WC $\geq 90 \mathrm{~cm}$ in men and $\geq 85 \mathrm{~cm}$ in women according to the Korean Society for the Study of Obesity. ${ }^{17)}$ Overweight and obesity were defined by the World Health Organization Asia-Pacific Guideline (overweight: $23.0 \leq \mathrm{BMI}<25.0 \mathrm{~kg} / \mathrm{m}^{2}$; obesity I: $25.0 \leq$ BMI $<30.0 \mathrm{~kg} / \mathrm{m}^{2}$; obesity II: BMI $\left.\geq 30.0 \mathrm{~kg} / \mathrm{m}^{2}\right) .{ }^{18)}$ We used the modified National Cholesterol Education Program-Adult Treatment Panel III (NCEP-ATP III) criteria to define MetS as the presence of three or more of the following components: (1) WC $\geq 90 \mathrm{~cm}$ in men and $\geq 85 \mathrm{~cm}$ in women, adopted from the Korean Society for the Study of Obesity criteria; (2) triglyceride (TG) level $\geq 150 \mathrm{mg} / \mathrm{dL}$; (3) highdensity lipoprotein cholesterol (HDLC) level $<40 \mathrm{mg} / \mathrm{dL}$ in men and $<50 \mathrm{mg} / \mathrm{dL}$ in women; (4) blood pressure $\geq 130 / 85 \mathrm{~mm} \mathrm{Hg}$ or current treatment for hypertension; and (5) fasting glucose level $100 \mathrm{mg} / \mathrm{dL}$ or a previous diagnosis of diabetes mellitus (DM). ${ }^{19)}$

Hypertension was diagnosed as a systolic blood pressure (SBP) $\geq 140$ $\mathrm{mm} \mathrm{Hg}$ or a diastolic blood pressure (DBP) $\geq 90 \mathrm{~mm} \mathrm{Hg}$ as measured during the health assessments or the presence of treated hypertension with lower readings. ${ }^{20)}$ Treated hypertension was defined as having been previously diagnosed with hypertension (based on International Classification of Disease 10th Revision [ICD-10] I10 guidelines) and receiving antihypertensive therapy based upon medical claims during the year when the participants completed the health assessment.

Dyslipidemia was diagnosed in patients with the presence of one of the following abnormal lipid profiles, according to the NCEP-ATP III: total cholesterol $\geq 240 \mathrm{mg} / \mathrm{dL}, \mathrm{TG} \geq 200 \mathrm{mg} / \mathrm{dL}$, or HDLC $<40 \mathrm{mg} / \mathrm{dL}$ in men ( $<50 \mathrm{mg} / \mathrm{dL}$ in women), a low-density lipoprotein cholesterol (LDLC) $\geq 160 \mathrm{mg} / \mathrm{dL}$ during their health assessments, or treated dyslipidemia. Treated dyslipidemia was defined as having been diagnosed with dyslipidemia (ICD-10 E78) and being prescribed cholesterol-lowering medications according to medical claims occurring in the same year when the participants received a health assessment.

DM was diagnosed as either a fasting blood glucose $\geq 126 \mathrm{mg} / \mathrm{dL}$ during the health assessments or treated diabetes. ${ }^{21)}$ Treated diabetes was defined as having been diagnosed with diabetes (ICD-10 E11) and using oral hypoglycemic agents or insulin.

\section{Statistical Analysis}

The participants were divided into two WC and five BMI groups as follows: WC group I (WC $<90 \mathrm{~cm}$ in men and $<85 \mathrm{~cm}$ in women), WC group II ( $\geq 90 \mathrm{~cm}$ in men and $\geq 85 \mathrm{~cm}$ in women), BMI group I (BMI $\left.<18.5 \mathrm{~kg} / \mathrm{m}^{2}\right)$, BMI group II ( $\geq 18.5$ to $\left.<23.0 \mathrm{~kg} / \mathrm{m}^{2}\right)$, BMI group III $(\geq 23.0$ to $<25.0 \mathrm{~kg} / \mathrm{m}^{2}$ ), BMI group IV ( $\geq 25.0$ to $<30.0 \mathrm{~kg} / \mathrm{m}^{2}$ ), and BMI group $\mathrm{V}\left(\geq 30.0 \mathrm{~kg} / \mathrm{m}^{2}\right)$. These WC and BMI categories were cross-tabulated to form 10 combinations of WC and BMI (WC*BMI) groups.

These categories allowed us to evaluate the clinical utility of combined WC and BMI in determining cardiovascular risk factors. A multivariable logistic regression was conducted to assess cardiovascular risk for MetS, hypertension, DM, and dyslipidemia, according to the status of central obesity and obesity. The adjusted odds ratios (ORs)

Table 1. Characteristics of participants by sex $(\mathrm{N}=328,789)$

\begin{tabular}{|c|c|c|}
\hline Characteristic & $\begin{array}{c}\text { Males } \\
(n=169,011)\end{array}$ & $\begin{array}{c}\text { Females } \\
(\mathrm{n}=159,778)\end{array}$ \\
\hline \multicolumn{3}{|l|}{ Age group (y) } \\
\hline $30-39$ & $38,507(22.8)$ & 20,092 (12.6) \\
\hline $40-49$ & 49,403 (29.2) & $46,623(29.2)$ \\
\hline $50-59$ & $43,242(25.6)$ & $46,351(29.0)$ \\
\hline $60-69$ & $23,979(14.2)$ & $28,254(17.7)$ \\
\hline$\geq 70$ & $13,880(8.2)$ & $18,458(11.6)$ \\
\hline \multicolumn{3}{|l|}{ Body mass index $\left(\mathrm{kg} / \mathrm{m}^{2}\right)$} \\
\hline$<18.5$ & $3,216(1.9)$ & $6,415(4.0)$ \\
\hline $18.5-23.0$ & $52,501(31.1)$ & $71,180(44.6)$ \\
\hline $23.0-25.0$ & $46,628(27.6)$ & $37,254(23.3)$ \\
\hline $25.0-30.0$ & $59,440(35.2)$ & $38,786(24.3)$ \\
\hline$\geq 30.0$ & $7,226(4.3)$ & $6,143(3.8)$ \\
\hline \multicolumn{3}{|l|}{ Waist circumference (cm) } \\
\hline$<90$ in men (<85 in women) & $128,112(75.8)$ & $128,820(80.6)$ \\
\hline$\geq 90$ in men ( $\geq 85$ in women) & 40,899 (24.2) & $30,958(19.4)$ \\
\hline \multicolumn{3}{|l|}{ Smoking } \\
\hline Never & $49,740(29.4)$ & $151,627(94.9)$ \\
\hline Former & $48,910(28.9)$ & $2,650(1.7)$ \\
\hline Current & $70,361(41.6)$ & $5,501(3.4)$ \\
\hline Alcohol (yes) & $114,625(67.8)$ & $37,986(23.8)$ \\
\hline Exercise (yes) & $100,316(59.4)$ & $76,490(47.9)$ \\
\hline \multicolumn{3}{|l|}{ Household income relative to the median (\%) } \\
\hline $0-30$ & 25,945 (15.4) & $42,185(26.4)$ \\
\hline $30-60$ & $39,681(23.5)$ & $40,314(25.2)$ \\
\hline $60-90$ & $73,206(43.3)$ & $54,383(34.0)$ \\
\hline $90-100$ & $30,179(17.9)$ & $22,896(14.3)$ \\
\hline \multicolumn{3}{|l|}{ Residential area } \\
\hline Seoul (metropolitan) & $31,170(18.5)$ & $31,264(19.6)$ \\
\hline Large city & $45,062(26.7)$ & $42,991(26.9)$ \\
\hline Small city & $78,965(46.8)$ & $70,997(44.5)$ \\
\hline Rural & $13,584(8.1)$ & $14,337(9.0)$ \\
\hline Systolic blood pressure (mm Hg) & $124.8 \pm 14.0$ & $120.2 \pm 15.4$ \\
\hline Diastolic blood pressure (mm Hg) & $78.1 \pm 9.7$ & $74.4 \pm 9.9$ \\
\hline Total cholesterol (mg/dL) & $196.9 \pm 36.6$ & $199.1 \pm 37.2$ \\
\hline Low-density lipoprotein cholesterol (mg/dL) & $115.2 \pm 34.1$ & $117.9 \pm 34.0$ \\
\hline High-density lipoprotein cholesterol (mg/dL) & $51.8 \pm 15.3$ & $58.6 \pm 17.8$ \\
\hline Triglycerides (mg/dL) & $154.8 \pm 104.7$ & $113.7 \pm 71.6$ \\
\hline Fasting glucose (mg/dL) & $101.7 \pm 26.9$ & $96.7 \pm 21.4$ \\
\hline
\end{tabular}

Values are presented as number (\%) or mean \pm standard deviation. 
and $95 \%$ confidence intervals (CIs) are given. We considered covariates to be age at enrollment, smoking status (never, former, or current smoker), exercise status (intensity of exercise response of "yes": $\geq 600$ metabolic equivalents of task-minutes per week), alcohol consumption (a response of "yes": more than 1 day a week), residential area according to 4 regions (Seoul, a metropolitan area in Korea, responses included large city, small city, and rural area) and household income ( $\leq 30 \%, 30 \%-60 \%, 60 \%-90 \%$, $>90 \%$ of the median). Analyses were performed with SAS Windows ver. 9.2 (SAS Institute Inc., Cary, NC, USA).

\section{RESULTS}

Clinical characteristics of the 328,789 participants by sex are presented in Table 1. Men had a higher mean value for SBP, DBP, total cholesterol, fasting glucose, and TG than women, whereas women had a higher value for LDLC and HDLC. The proportion of central obesity was $24.2 \%$ in men and $19.4 \%$ in women. The incidences of being overweight, obese I, and obese II were $27.6 \%, 35.2 \%$ and $4.3 \%$ in men and
$23.3 \%, 24.3 \%$ and $3.8 \%$ in women, respectively.

Table 2 presents the proportions of cardiovascular risk factors with the combinations of WC and BMI in men and women. The total study population was divided into 10 groups. As expected, among men with a WC $<90 \mathrm{~cm}$, the proportion of MetS, hypertension, DM, treated dyslipidemia, and dyslipidemia increased with increases in BMI. Among women with a $\mathrm{WC}<85 \mathrm{~cm}$, the proportion of MetS, hypertension, treated DM, DM, and dyslipidemia in women increased with increases in BMI. Centrally obese participants (WC $\geq 90 \mathrm{~cm}$ in men and $85 \mathrm{~cm}$ in women) had a higher mean proportion of all cardiovascular risk factors compared to non-centrally obese participants of both sexes. The mean proportion of DM was the lowest among the mean proportion of all cardiovascular risk factors in each group for both sexes.

Table 3 summarizes the association of combined BMI and WC with cardiovascular risk factors after participants were divided into 10 groups. Noticeably, the ORs were often higher in men with a WC $\geq 90$ $\mathrm{cm}$ and women with a WC $\geq 85 \mathrm{~cm}$ than in men with a $\mathrm{WC}<90 \mathrm{~cm}$ and women with a WC $<85 \mathrm{~cm}$ in each quintile of BMI. For instance, in

Table 2. Proportions of cardiovascular risk factors with the combined use of BMI and WC in Koreans

\begin{tabular}{|c|c|c|c|c|c|c|c|c|c|}
\hline \multirow[b]{2}{*}{ Variable } & \multirow{2}{*}{$\begin{array}{c}\mathrm{BMl} \\
\left(\mathrm{kg} / \mathrm{m}^{2}\right)\end{array}$} & \multirow{2}{*}{$\begin{array}{l}\text { No. of participants } \\
\quad(n=328,789)\end{array}$} & \multicolumn{7}{|c|}{ No. (\%) of cardiovascular risk factors } \\
\hline & & & $\begin{array}{c}\text { MetS } \\
(n=70,684)\end{array}$ & $\begin{array}{l}\text { Treated HTN } \\
(n=51,340)\end{array}$ & $\begin{array}{c}\text { HTN } \\
(n=83,093)\end{array}$ & $\begin{array}{l}\text { Treated DM } \\
(n=16,761)\end{array}$ & $\begin{array}{c}\mathrm{DM} \\
(\mathrm{n}=31,054)\end{array}$ & $\begin{array}{l}\text { Treated DL } \\
(n=13,658)\end{array}$ & $\begin{array}{c}\mathrm{DL} \\
(\mathrm{n}=113,004)\end{array}$ \\
\hline Men & & 169,011 & & & & & & & \\
\hline \multicolumn{10}{|l|}{$W C<90 \mathrm{~cm}$} \\
\hline & $<18.5$ & 3,209 & $120(3.74)$ & $229(7.1)$ & $467(14.6)$ & $123(3.8)$ & $230(7.2)$ & $53(1.7)$ & $517(16.1)$ \\
\hline & $18.5-23.0$ & 51,744 & $4,169(8.06)$ & $5,301(10.2)$ & $9,804(18.9)$ & $2,331(4.5)$ & $4,421(8.5)$ & $1,117(2.2)$ & $13,864(26.8)$ \\
\hline & $23.0-25.0$ & 41,902 & $5,988(14.29)$ & $5,691(13.6)$ & $9,980(23.8)$ & $2,101(5.0)$ & $4,193(10.0)$ & $1,234(2.9)$ & $16,535(39.5)$ \\
\hline & $25.0-30.0$ & 30,911 & $6,197(20.05)$ & $4,561(14.8)$ & $8,618(27.9)$ & $1,399(4.5)$ & $3,181(10.3)$ & $945(3.1)$ & $14,647(47.4)$ \\
\hline & $\geq 30.0$ & 346 & $112(32.37)$ & $51(14.7)$ & 129 (37.3) & $10(2.9)$ & $45(13.0)$ & $12(3.5)$ & $200(57.8)$ \\
\hline & Overall & 128,112 & $16,586(12.9)$ & $15,833(12.4)$ & 28,998 (22.6) & $5,965(4.7)$ & $12,070(9.4)$ & $3,361(2.6)$ & $45,763(35.7)$ \\
\hline \multicolumn{10}{|l|}{$W C \geq 90 \mathrm{~cm}$} \\
\hline & $<18.5$ & 7 & $4(57.14)$ & $2(28.6)$ & $4(57.1)$ & - & - & - & $2(28.6)$ \\
\hline & $18.5-23.0$ & 757 & $388(51.25)$ & $191(25.2)$ & $302(39.9)$ & $70(9.2)$ & $137(18.1)$ & $20(2.6)$ & $320(42.3)$ \\
\hline & $23.0-25.0$ & 4,726 & 2,537 (53.68) & $1,115(23.6)$ & $1,747(37.0)$ & $488(10.3)$ & $847(17.9)$ & $210(4.4)$ & $2,213(46.8)$ \\
\hline & $25.0-30.0$ & 28,529 & $17,620(61.76)$ & 6,212 (21.8) & $10,732(37.6)$ & $2,189(7.7)$ & 4,495 (15.8) & $988(3.5)$ & $15,242(53.4)$ \\
\hline & $\geq 30.0$ & 6,880 & 4,971 (72.25) & $1,499(21.8)$ & 3,068 (44.6) & $485(7.0)$ & $1,246(18.1)$ & $199(2.9)$ & $4,226(61.4)$ \\
\hline & Overall & 40,899 & $25,520(62.4)$ & $9,019(22.1)$ & $15,853(38.8)$ & $3,232(7.9)$ & 6,725 (16.4) & $1,417(3.5)$ & 22,003 (53.8) \\
\hline Women & & 159,778 & & & & & & & \\
\hline \multicolumn{10}{|l|}{$W C<85 \mathrm{~cm}$} \\
\hline & $<18.5$ & 6,389 & 142 (2.22) & $355(5.6)$ & 559 (8.7) & $103(1.6)$ & $181(2.8)$ & 142 (2.2) & 768 (12.0) \\
\hline & $18.5-23.0$ & 69,730 & 3,962 (5.68) & $6,644(9.5)$ & 9,987 (14.3) & $2,005(2.9)$ & $3,102(4.4)$ & $3,113(4.5)$ & $14,477(20.8)$ \\
\hline & $23.0-25.0$ & 32,405 & 3,847 (11.87) & $5,573(17.2)$ & $7,948(24.5)$ & $1,398(4.3)$ & $2,239(6.9)$ & $2,049(6.3)$ & $10,004(30.9)$ \\
\hline & $25.0-30.0$ & 19,808 & 3,213 (16.22) & $4,184(21.1)$ & $6,036(30.5)$ & $900(4.5)$ & $1,641(8.3)$ & $1,288(6.5)$ & $6,934(35.0)$ \\
\hline & $\geq 30.0$ & 488 & 107 (21.93) & $101(20.7)$ & $164(33.6)$ & $25(5.1)$ & $45(9.2)$ & $19(3.9)$ & 183 (37.5) \\
\hline & Overall & 128,820 & $11,271(8.7)$ & 16,857 (13.1) & 24,694 (19.2) & $4,431(3.4)$ & $7,208(5.6)$ & $6,611(5.1)$ & $32,366(25.1)$ \\
\hline \multicolumn{10}{|l|}{$W C \geq 85 \mathrm{~cm}$} \\
\hline & $<18.5$ & 26 & $13(50.00)$ & $9(34.6)$ & $11(42.3)$ & $5(19.2)$ & $8(30.8)$ & - & $11(42.3)$ \\
\hline & $18.5-23.0$ & 1,450 & $639(44.07)$ & $379(26.1)$ & $522(36.0)$ & $148(10.2)$ & $207(14.3)$ & $91(6.3)$ & 509 (35.1) \\
\hline & $23.0-25.0$ & 4,849 & 2,374 (48.96) & 1,368 (28.2) & $1,876(38.7)$ & 494 (10.2) & $697(14.4)$ & $379(7.8)$ & $1,945(40.1)$ \\
\hline & $25.0-30.0$ & 18,978 & $10,643(56.08)$ & $6,020(31.7)$ & $8,339(43.9)$ & $1,875(9.9)$ & 3,023 (15.9) & $1,425(7.5)$ & $8,034(42.3)$ \\
\hline & $\geq 30.0$ & 5,655 & 3,638 (64.33) & $1,855(32.8)$ & $2,800(49.5)$ & $611(10.8)$ & $1,116(19.7)$ & $374(6.6)$ & $2,373(42.0)$ \\
\hline & Overall & 30,958 & $17,307(55.9)$ & 9,631 (31.1) & $13,548(43.8)$ & $3,133(10.1)$ & 5,051 (16.3) & $2,269(7.3)$ & $12,872(41.6)$ \\
\hline
\end{tabular}

The total study population was divided into 10 subgroups of combinations of BMI and WC. Treated HTN, DM and DL: participants who have already been diagnosed and are currently on medication. HTN, DM and DL: participants who had already been diagnosed and are on medication, or who met each diagnostic criterion.

BMI, body mass index; WC, waist circumference; MetS, metabolic syndrome; HTN, hypertension; DM, diabetes mellitus; DL, dyslipidemia. 
Table 3. ORs (95\% confidence interval) of cardiovascular risk factors for the combined use of BMl and WC in Koreans

\begin{tabular}{|c|c|c|c|c|c|}
\hline \multirow{2}{*}{ Variable } & \multirow{2}{*}{ BMI $\left(\mathrm{kg} / \mathrm{m}^{2}\right)$} & \multicolumn{4}{|c|}{ ORs of cardiovascular risk factors } \\
\hline & & Metabolic syndrome & Hypertension & Diabetes mellitus & Dyslipidemia \\
\hline \multicolumn{6}{|l|}{ Men } \\
\hline \multicolumn{6}{|l|}{$W C<90 \mathrm{~cm}$} \\
\hline & $<18.5$ & $0.41(0.34-0.50)$ & $0.63(0.56-0.69)$ & $0.73(0.64-0.84)$ & $0.50(0.45-0.55)$ \\
\hline & $18.5-23.0$ & 1.00 & 1.00 & 1.00 & 1.00 \\
\hline & $23.0-25.0$ & $1.97(1.89-2.05)$ & $1.44(1.39-1.49)$ & $1.25(1.20-1.31)$ & $1.83(1.78-1.88)$ \\
\hline & $25.0-30.0$ & $3.10(2.97-3.24)$ & $2.08(2.01-2.16)$ & $1.45(1.38-1.53)$ & $2.56(2.49-2.64)$ \\
\hline & $\geq 30.0$ & $6.32(5.02-7.95)$ & $4.21(3.34-5.30)$ & $2.34(1.69-3.24)$ & $3.90(3.14-4.84)$ \\
\hline \multicolumn{6}{|l|}{$W C \geq 90 \mathrm{~cm}$} \\
\hline & $<18.5$ & $14.50(3.22-65.28)$ & $6.99(1.45-33.55)$ & - & $0.98(0.19-5.07)$ \\
\hline & $18.5-23.0$ & $10.79(9.31-12.50)$ & $1.82(1.56-2.12)$ & $1.66(1.38-2.01)$ & $2.03(1.75-2.35)$ \\
\hline & $23.0-25.0$ & $12.65(11.84-13.51)$ & $1.94(1.82-2.08)$ & $1.88(1.73-2.04)$ & $2.45(2.31-2.61)$ \\
\hline & $25.0-30.0$ & $19.45(18.68-20.24)$ & $2.76(2.67-2.86)$ & $2.04(1.95-2.13)$ & $3.23(3.14-3.33)$ \\
\hline & $\geq 30.0$ & $35.95(33.75-38.30)$ & $5.70(5.38-6.03)$ & $3.51(3.26-3.77)$ & $4.59(4.36-4.84)$ \\
\hline \multirow{2}{*}{\multicolumn{6}{|c|}{$\begin{array}{l}\text { Women } \\
\text { WC }<85 \mathrm{~cm}\end{array}$}} \\
\hline & & & & & \\
\hline & $<18.5$ & $0.43(0.36-0.51)$ & $0.67(0.61-0.74)$ & $0.75(0.64-0.87)$ & $0.62(0.57-0.67)$ \\
\hline & $18.5-23.0$ & 1.00 & 1.00 & 1.00 & 1.00 \\
\hline & $23.0-25.0$ & $1.94(1.85-2.03)$ & $1.61(1.55-1.66)$ & $1.32(1.25-1.40)$ & $1.48(1.44-1.53)$ \\
\hline & $25.0-30.0$ & $2.79(2.65-2.93)$ & $2.23(2.15-2.32)$ & $1.60(1.50-1.71)$ & 1.79 (1.73-1.86) \\
\hline & $\geq 30.0$ & $5.22(4.18-6.52)$ & $4.17(3.39-5.12)$ & $2.43(1.77-3.33)$ & 2.47 (2.05-2.99) \\
\hline \multicolumn{6}{|l|}{$W C \geq 85 \mathrm{~cm}$} \\
\hline & $<18.5$ & 7.25 (3.31-15.88) & $1.14(0.51-2.55)$ & $3.87(1.66-9.01)$ & $1.74(0.79-3.80)$ \\
\hline & 18.5-23.0 & $8.99(8.02-10.08)$ & $1.67(1.48-1.88)$ & $2.10(1.79-2.45)$ & 1.55 (1.39-1.74) \\
\hline & $23.0-25.0$ & $11.26(10.52-12.04)$ & $2.01(1.88-2.15)$ & $2.17(1.98-2.38)$ & 1.87 (1.76-1.99) \\
\hline & $25.0-30.0$ & $16.24(15.53-16.97)$ & $2.91(2.80-3.02)$ & $2.64(2.50-2.79)$ & $2.11(2.04-2.19)$ \\
\hline & $\geq 30.0$ & $29.22(27.36-31.20)$ & $5.57(5.23-5.93)$ & $4.35(4.02-4.70)$ & $2.41(2.28-2.55)$ \\
\hline
\end{tabular}

The total study population was divided into 10 subgroups of combinations of BMl and WC. Using the combination group with a WC $<90 \mathrm{~cm}$ in men (WC $<85 \mathrm{~cm}$ in women) and a BMl 18.5 to $23.0 \mathrm{~kg} / \mathrm{m}^{2}$ ( $\mathrm{n}=51,744$ in men, $n=3,962$ in women) as the referent $(\mathrm{OR}=1)$, the ORs are shown. Adjusted for age, smoking status, exercise status, alcohol consumption, residential area, and household income.

$\mathrm{OR}$, odds ratio; $\mathrm{BMI}$, body mass index; WC, waist circumference.

women, the ORs ( $95 \%$ CIs) for DM in the group with a WC $<85 \mathrm{~cm}$ versus those with a WC $\geq 85 \mathrm{~cm}$ were 1.00 versus 2.10 (range, 1.79-2.45), 1.32 (range, 1.25-1.40) versus 2.17 (range, 1.98-2.38), 1.60 (range, 1.501.71) versus 2.64 (range, 2.50-2.79), and 2.43 (range, 1.77-3.33) versus 4.35 (range, 4.02-4.70) for BMI groups I, II, III, IV, and V, respectively. Compared to the group with a normal WC and a normal BMI, the centrally obese and highest BMI group (BMI $\geq 30.0 \mathrm{~kg} / \mathrm{m}^{2}$ ) were associated with a nearly 36 -fold greater risk of MetS in men and a 29-fold greater risk in women. In contrast, for women, the presence of central obesity had less influence on hypertension and dyslipidemia than it did on MetS and DM, because the increase of ORs in hypertension and dyslipidemia was less remarkable than the increase of ORs in MetS and $\mathrm{DM}$ in the group with a WC $\geq 85 \mathrm{~cm}$ compared with those with a WC $<85 \mathrm{~cm}$.

Figure 2 shows the correlation of cardiovascular risk factors with the status of central obesity and obesity. The total study population was divided into four subgroups with different combinations of BMI and WC according to the status of central obesity and obesity.

Compared to men and women with a WC $<90 \mathrm{~cm}$ and $<85 \mathrm{~cm}$, respectively, and a BMI $<25.0 \mathrm{~kg} / \mathrm{m}^{2}$, the participants who were obese (BMI $\geq 25.0 \mathrm{~kg} / \mathrm{m}^{2}$ ) or centrally obese (WC $\geq 90 \mathrm{~cm}$ in men and $\geq 85 \mathrm{~cm}$ in women) had a slightly increased correlation with all cardiovascular risk factors; at the same time, participants who were centrally obese (WC $\geq 90$ in men and $>85 \mathrm{~cm}$ in women) and obese (BMI $\geq 25.0 \mathrm{~kg} / \mathrm{m}^{2}$ ) had the strongest correlation of all cardiovascular risk factors. For example, in men, the adjusted ORs (95\% CIs) for MetS were 2.26 (range, 2.18-2.34) in the group with a WC $<90 \mathrm{~cm}$ and a BMI $\geq 25.0 \mathrm{~kg} / \mathrm{m}^{2}, 9.11$ (range, 8.60-9.65) in the group with a WC $\geq 90 \mathrm{~cm}$ and a BMI $<25.0 \mathrm{~kg}$ / $\mathrm{m}^{2}$, and 15.73 (range, 15.26-16.21) in the centrally obese and obese group (BMI $\geq 25.0 \mathrm{~kg} / \mathrm{m}^{2}$ ).

In addition, those that were centrally obese had a significantly increased risk for MetS and DM compared to hypertension and dyslipidemia among both sexes, because the difference in ORs between the group with a WC $<90 \mathrm{~cm}$ in men ( $<85 \mathrm{~cm}$ in women) and a $\mathrm{BMI} \geq 25.0$ $\mathrm{kg} / \mathrm{m}^{2}$ and the group with a WC $\geq 90 \mathrm{~cm}$ in men ( $\geq 85 \mathrm{~cm}$ in women) and a $\mathrm{BMI}<25.0 \mathrm{~kg} / \mathrm{m}^{2}$ was positively more remarkable for the risk factors MetS and DM.

\section{DISCUSSION}

As the Korean population is rapidly aging, it is expected that the prevalence of CVD will continue to increase. ${ }^{22,23)}$ A system should be estab- 

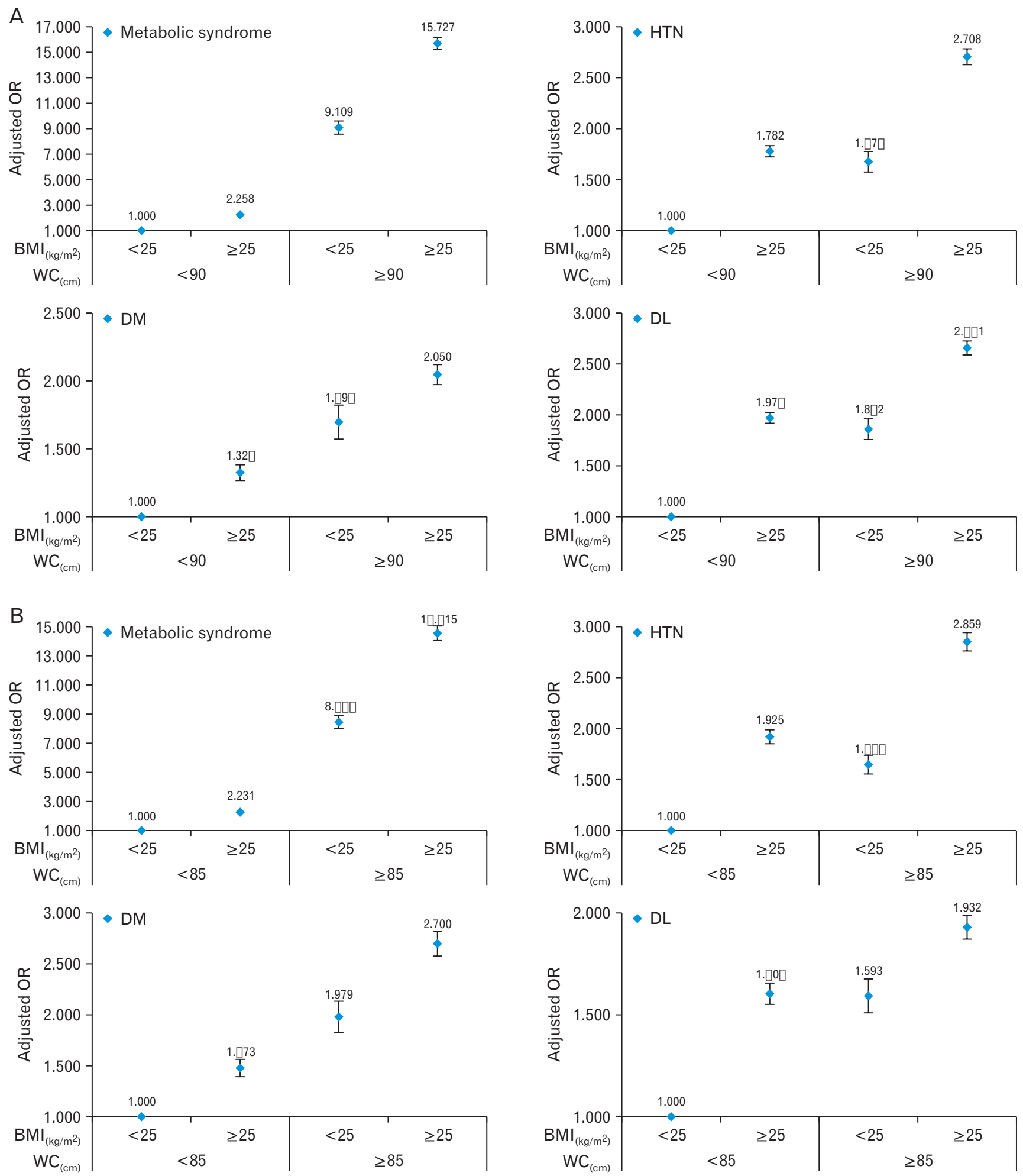

Figure 2. ORs (95\% confidence interval) of cardiovascular risk factors using combined BMl and WC in males (A) and females (B). The total study population was divided into four subgroups according to the participants' status of central obesity and obesity. Using the combination group with a WC $<90$ in males (WC $<85$ in females) and a BMl $<25$ ( $n=96,855$ in males, $n=108,524$ in females) as the referent $(O R=1)$, the ORs are shown. The P-values of all ORs were $P<0.05$ and were adjusted for age, smoking status, exercise status, and alcohol consumption. OR, odds ratio; WC, waist circumference; BMI, body mass index; MetS, metabolic syndrome; HTN, hypertension; DM, diabetes mellitus; DL, dyslipidemia. 
lished to prevent CVD and warn the aging population of the dangers of CVD. This study investigated the prevalence of central obesity and obesity as well as the correlation of cardiovascular risk factors by crosstabulating central obesity with multiple BMI categories.

The 2014 Korea National Health and Nutrition Examination Survey (KNHANES) reported that the prevalence of central obesity was $23.1 \%$ ( $26.0 \%$ in men and $20.2 \%$ in women), while the incidence of obesity was $31.5 \%$ (37.7\% in men and $25.3 \%$ in women). ${ }^{24)}$ Similar to the 2014 KNHANES, our results showed that central obesity and obesity were more prevalent in men than in women (Table 1); the proportion of central obesity and obesity were $24.2 \%$ and $39.5 \%$ in men and $19.4 \%$ and $28.1 \%$ in women, respectively.

Previous studies on cross-sectional associations were conducted to investigate variables to determine which was better among anthropometric indexes, including BMI, WC, and waist-to-height ratio, to predict a patient's cardiometabolic risk. ${ }^{6,11,25,26)}$ In this study, we used both BMI and WC as important anthropometric indexes for predicting cardiovascular risk factors on the premise that a stronger positive association exists between cardiovascular risk factors, such as hypertension and lipid and glucose concentrations, when both BMI and WC are considered than with BMI or WC alone. Hou et al. ${ }^{14)}$ reported the clinical advantage of using combined WC and BMI categories in identifying the risks for CMD and CVD. Their study found that a combination of WC and BMI categories significantly increased the power of identifying CMD risk compared to separate WC or BMI categories; these authors suggested that WC can be a helpful indicator for DM, and that BMI is closely related with hypertension in China. Our study is consistent with the previous study in that the combination of BMI and WC significantly increased the correlation of cardiovascular risk factors. According to Table 3, both BMI and WC likely had a positive relationship with each cardiovascular risk factor in both sexes; the ORs increased with increases in BMI and WC, except for the group with a BMI $<18.5 \mathrm{~kg} / \mathrm{m}^{2}$ and a WC $\geq 90 \mathrm{~cm}$ in men ( $\geq 85 \mathrm{~cm}$ in women) because the group size was so small that the results were not statistically significant. The highest combination WC and BMI group (WC $\geq 90 \mathrm{~cm}$ in men and $\geq 85 \mathrm{~cm}$ in women and $\mathrm{BMI} \geq 30.0 \mathrm{~kg} / \mathrm{m}^{2}$ ) was the one most strongly associated with all cardiovascular risk factors.

In addition, the presence of central obesity positively influenced each type of cardiovascular risk, as the ORs were mostly higher in the group with a WC $\geq 90 \mathrm{~cm}$ in men ( $\geq 85 \mathrm{~cm}$ in women) than in the group with a WC $<90 \mathrm{~cm}$ in men ( $<85 \mathrm{~cm}$ in women) in each quintile of BMI. Similar to the previous study, WC was closely related with DM as well as MetS in this study. ${ }^{9,14,27)}$ In particular, it could be suggested that the presence of central obesity had a lesser effect on the risk of hypertension and dyslipidemia in women than the risk for MetS and DM.

The correlation of cardiovascular risk factors was the most remarkable in participants who were both centrally obese and obese at the same time (Figure 2). Participants who were either obese or centrally obese were more likely to have an increased risk of CVD than participants who were not centrally obese or obese. The Centrally obese groups had a significantly greater risk of MetS and DM than those with hypertension and dyslipidemia in all sexes (Figure 2). Based upon these findings, it is necessary to alert participants who are obese, centrally obese, or both that they have an increased risk for CVD, especially participants who are both centrally obese and obese. As mentioned above, centrally obese participants should be made aware of the risk for MetS and DM; these findings would be very appropriate for practical health education.

Our study had some limitations. First, this study only combined BMI and WC without comparing separate BMI and WC groups. Second, as the magnitude of interaction between BMI and WC was not examined in this study, the correlation of a combined WC and BMI on each cardiovascular risk factor cannot be quantified through a comparison of the ORs of these cardiovascular risk factors. Third, outcome variables in this study would be significantly influenced by age, so further study would be required to determine age-adjusted prevalence of disease. Fourth, the OR might be exaggerated because MetS as an outcome variable has a high prevalence. Fifth, this study was a cross-sectional survey, and it may preclude the identification of any causal relationship in each group. Finally, we depended on a subjective survey using questionnaires, so we cannot rule out recall bias.

The strength of this study was that it used nationally representative data from the KNHIS, and the findings are therefore generalizable to all Koreans. This was the first attempt to investigate the correlation of cardiovascular risk factors by considering the interaction of both BMI and WC simultaneously. These findings lead to significant speculation that the clinical utilization of combining both WC and BMI may provide a useful index for preventing CVD in Korea. Our study also provides evidence that cardiovascular risk determined by using a combined WC and BMI divided into 10 groups or 4 groups, respectively, would be worthwhile to design effective strategies for predicting and preventing CVD.

In conclusion, the purpose of this study was to investigate the clinical advantage of using WC and BMI categories simultaneously in identifying cardiovascular risk in Koreans. This study emphasized that the combination of both BMI and WC can help identify individuals at increased risk for developing CVD.

\section{CONFLICT OF INTEREST}

No potential conflict of interest relevant to this article was reported.

\section{ACKNOWLEDGMENTS}

The authors would like to thank the Korean National Health Insurance Service.

\section{REFERENCES}

1. Must A, Spadano J, Coakley EH, Field AE, Colditz G, Dietz WH. The disease burden associated with overweight and obesity. JAMA 1999;282:1523-9. 
2. Lamon-Fava S, Wilson PW, Schaefer EJ. Impact of body mass index on coronary heart disease risk factors in men and women. The Framingham Offspring Study. Arterioscler Thromb Vasc Biol 1996;16:1509-15.

3. Brown CD, Higgins M, Donato KA, Rohde FC, Garrison R, Obarzanek E, et al. Body mass index and the prevalence of hypertension and dyslipidemia. Obes Res 2000;8:605-19.

4. Wilson PW, D'Agostino RB, Sullivan L, Parise H, Kannel WB. Overweight and obesity as determinants of cardiovascular risk: the Framingham experience. Arch Intern Med 2002;162:1867-72.

5. Wang F, Wu S, Song Y, Tang X, Marshall R, Liang M, et al. Waist circumference, body mass index and waist to hip ratio for prediction of the metabolic syndrome in Chinese. Nutr Metab Cardiovasc Dis 2009;19: 542-7.

6. Cheong KC, Ghazali SM, Hock LK, Subenthiran S, Huey TC, Kuay LK, et al. The discriminative ability of waist circumference, body mass index and waist-to-hip ratio in identifying metabolic syndrome: variations by age, sex and race. Diabetes Metab Syndr 2015;9:74-8.

7. Han TS, van Leer EM, Seidell JC, Lean ME. Waist circumference action levels in the identification of cardiovascular risk factors: prevalence study in a random sample. BMJ 1995;311:1401-5.

8. Wei M, Gaskill SP, Haffner SM, Stern MP. Waist circumference as the best predictor of noninsulin dependent diabetes mellitus (NIDDM) compared to body mass index, waist/hip ratio and other anthropometric measurements in Mexican Americans: a 7-year prospective study. Obes Res 1997;5:16-23.

9. Huang LH, Liao YL, Hsu CH. Waist circumference is a better predictor than body mass index of insulin resistance in type 2 diabetes. Obes Res Clin Pract 2012;6:e263-346.

10. Welborn TA, Dhaliwal SS. Preferred clinical measures of central obesity for predicting mortality. Eur J Clin Nutr 2007;61:1373-9.

11. Lam BC, Koh GC, Chen C, Wong MT, Fallows SJ. Comparison of body mass index (BMI), body adiposity index (BAI), waist circumference (WC), waist-to-hip ratio (WHR) and waist-to-height ratio (WHtR) as predictors of cardiovascular disease risk factors in an adult population in Singapore. PLoS One 2015;10:e122985.

12. Christian AH, Mochari H, Mosca LJ. Waist circumference, body mass index, and their association with cardiometabolic and global risk. J Cardiometab Syndr 2009;4:12-9.

13. Du SM, Ma GS, Li YP, Fang HY, Hu XQ, Yang XG, et al. Relationship of body mass index, waist circumference and cardiovascular risk factors in Chinese adult. Biomed Environ Sci 2010;23:92-101.

14. Hou X, Lu J, Weng J, Ji L, Shan Z, Liu J, et al. Impact of waist circumference and body mass index on risk of cardiometabolic disorder and cardiovascular disease in Chinese adults: a national diabetes and metabolic disorders survey. PLoS One 2013;8:e57319.

15. Sung KC, Ryu S, Reaven GM; Health Screening Group at Kangbuk Samsung Hospital. Relationship between obesity and several cardio- vascular disease risk factors in apparently healthy Korean individuals: comparison of body mass index and waist circumference. Metabolism 2007;56:297-303.

16. Lee J, Lee JS, Park SH, Shin SA, Kim K. Cohort profile: the National Health Insurance Service-National Sample Cohort (NHIS-NSC), South Korea. Int J Epidemiol 2017;46:e15.

17. Lee SY, Park HS, Kim DJ, Han JH, Kim SM, Cho GJ, et al. Appropriate waist circumference cutoff points for central obesity in Korean adults. Diabetes Res Clin Pract 2007;75:72-80.

18. World Health Organization. The Asia-Pacific perspective: redefining obesity and its treatment. Sydney: Health Communications Australia; 2000.

19. Expert Panel on Detection, Evaluation, and Treatment of High Blood Cholesterol in Adults. Executive summary of the third report of the National Cholesterol Education Program (NCEP) Expert Panel on Detection, Evaluation, and Treatment of High Blood Cholesterol in Adults (Adult Treatment Panel III). JAMA 2001;285:2486-97.

20. Guidelines Subcommittee. 1999 World Health Organization-International Society of Hypertension guidelines for the management of hypertension. J Hypertens 1999;17:151-83.

21. Alberti KG, Zimmet PZ. Definition, diagnosis and classification of diabetes mellitus and its complications: part 1: diagnosis and classification of diabetes mellitus provisional report of a WHO consultation. Diabet Med 1998;15:539-53.

22. Park JH, Lim S, Lim JY, Kim KI, Han MK, Yoon IY, et al. An overview of the Korean longitudinal study on health and aging. Psychiatry Investig 2007;4:84-95.

23. Kwon HS, Park YM, Lee HJ, Lee JH, Choi YH, Ko SH, et al. Prevalence and clinical characteristics of the metabolic syndrome in middle-aged Korean adults. Korean J Intern Med 2005;20:310-6.

24. Ministry of Health and Welfare. Korea health statistics 2014: Korea National Health and Nutrition Examination Survey (KNHANES Vl-2). Sejong: Ministry of Health and Welfare; 2015.

25. Grober-Gratz D, Widhalm K, de Zwaan M, Reinehr T, Bluher S, Schwab $\mathrm{KO}$, et al. Body mass index or waist circumference: which is the better predictor for hypertension and dyslipidemia in overweight/obese children and adolescents?: association of cardiovascular risk related to body mass index or waist circumference. Horm Res Paediatr 2013;80: 170-8.

26. Li WC, Chen IC, Chang YC, Loke SS, Wang SH, Hsiao KY. Waist-toheight ratio, waist circumference, and body mass index as indices of cardiometabolic risk among 36,642 Taiwanese adults. Eur J Nutr 2013;52:57-65.

27. Gharipour M, Sarrafzadegan N, Sadeghi M, Andalib E, Talaie M, Shafie D, et al. Predictors of metabolic syndrome in the Iranian population: waist circumference, body mass index, or waist to hip ratio? Cholesterol 2013;2013:198384. 